\title{
Assessment of an outreach street-based HIV rapid testing programme as a strategy to promote early diagnosis: a comparison with two surveillance systems in Spain, 2008-2011
}

M J Belza',2, J Hoyos (jhoyos@isciii.es) 2,3, S Fernández-Balbuena ${ }^{2}$, A Diaz ${ }^{2,3,4}$, M J Bravo ${ }^{2,3}$, L de la Fuente ${ }^{2,3}$, the Madrid HIV rapid testing group ${ }^{5}$

1. Escuela Nacional de Sanidad, Instituto de Salud Carlos III, Madrid, Spain

2. CIBER de Epidemiología y Salud Publica, Madrid, Spain

3. Centro Nacional de Epidemiologia, Instituto de Salud Carlos III, Madrid, Spain

4. Ministerio de Sanidad, Servicios Sociales e Igualdad, Spain

5. Members of the group are listed at the end of the article

Belza MJ, Hoyos J, Fernández-Balbuena S, Diaz A, Bravo MJ, de la Fuente L, the Madrid HIV rapid testing group. Assessment of an outreach street-based HIV rapid testing programme as a strategy to promote early diagnosis: a comparison with two surveillance systems in Spain, 2008-2011. Euro Surveill. 2015;20(14):pii=21089. Available online: http://www.eurosurveillance.org/ViewArticle. aspx?Articleld=21089

We assess the added value of a multisite, street-based HIV rapid testing programme by comparing its results to pre-existing services and assessing its potential to reduce ongoing transmission. Between 2008 and 2011, 8,923 individuals underwent testing. We compare outcomes with those of a network of 20 sexually transmitted infections (STI)/HIV clinics (EPI-VIH) and the Spanish National HIV Surveillance System (SNHSS); evaluate whether good visibility prompts testing and assess whether it reaches under-tested populations. $89.2 \%$ of the new infections were in men who have sex with men (MSM) vs $78.0 \%$ in EPI-VIH and $56.0 \%$ in SNHSS. $83.6 \%$ of the MSM were linked to care and $20.9 \%$ had $<350$ CD4 HIV prevalence was substantially lower than in EPI-VIH. $56.5 \%$ of the HIV-positive MSM tested because they happened to see the programme, $18.4 \%$ were previously untested and $26.3 \%$ had their last test $\geq 2$ years ago. The programme provided linkage to care and early diagnosis mainly to MSM but attendees presented a lower HIV prevalence than EPIVIH. From a cost perspective it would benefit from being implemented in locations highly frequented by MSM. Conversely, its good visibility led to reduced periods of undiagnosed infection in a high proportion of MSM who were not testing with the recommended frequency.

\section{Introduction}

In European countries with HIV epidemics similar to Spain's [1,2], between 20 and $35 \%$ of the HIV-infected population remains undiagnosed [3]. Of the new diagnoses reported in Spain in $2012,47.6 \%$ had a CD4 count under 350 cells/ $\mu \mathrm{L}$ [4]. Late presenters have both higher morbidity and mortality $[5,6]$ and higher rates of transmission than those who present early [7], therefore, promoting earlier diagnosis is a top priority to fight the epidemic [8].

In Spain, HIV testing is a non-routine procedure and, until recently, has been performed at all levels of the public health system, confidentially and free of charge, when requested by the patient or when considered necessary by the health provider. However, recent regulatory changes limit its access to migrants with illegal administrative status [9]. In some cities, testing is also offered in HIV-sexually transmitted infection (STI) clinics where it is also performed confidentially and free of charge.

Additionally, programmes offering rapid testing in non-clinical settings have proliferated in recent years. They are very heterogeneous in terms of target population, appointment requirement, duration of the counselling provided and type of rapid test used, but most are carried out at the premises of the communitybased organisations (CBO) that run them. Despite their expansion in recent years, their effectiveness in terms of seropositivity rates, linkage to care and capacity for promoting early diagnosis have rarely been externally evaluated, and their outcomes have rarely been compared with clinical settings.

Given the fixed nature of these programmes' venues, they reach people who necessarily perceive themselves at risk of being infected or who have interiorised the routine of testing periodically. Conversely, they might miss people with low risk perception, who do not feel the need to be tested. Offering rapid testing in highly visible locations could promote diagnosis in populations that do not actively seek testing in other venues. 
Testing is offered free of charge in a wide range of settings in Spain, and this paper aims to appraise the added value of a multi-site outreach programme offering rapid HIV testing in the street. To do this, we first analyse the characteristics of the population tested and the programme's capacity to reach people and link them to care early in the course of HIV infection and compare results against existing services. Second, we determine whether those diagnosed may constitute a population that is either not seeking HIV testing or testing too infrequently, and discuss to what extent the programme reduces time from infection to diagnosis.

\section{Methods}

\section{Setting and study period}

The programme was run by Madrid Positivo, a nongovernmental organisation and it was conducted during three periods: May 2008-December 2008 (season 1, 62 days in total), July 2009-July 2010 (season 2, 65 days) and November 2010-December 2011 (season 3, 35 days). In all three seasons, a mobile unit was located in Chueca, a busy commercial city-centre neighbourhood of Madrid frequented by young people, with a high proportion of gay residents and a high number of gay businesses (hereafter referred to as 'the gay neighbourhood'). It was also deployed in a Madrid neighbourhood with high migrant concentration (hereafter referred to as 'the migrant neighbourhood') (season 3) and in locations outside the city of Madrid with no relation to the gay scene (season 2-3) (additional data available upon request). The programme usually operated in the afternoon, and on certain days throughout the day. The regularity and the days on which the programme was implemented depended on permissions granted by local authorities to deploy the mobile unit in public spaces.

\section{Data collection, rapid test results and linkage} to care procedures

Individuals signed an informed consent and entered the mobile unit, where a nurse or doctor completed a brief pre-counselling session, and performed the test (Determine HIV-1/2 test). While waiting for the result, individuals completed an anonymous self-administered paper-based questionnaire code linked to their test (sections used available from authors upon request). The core survey was the same throughout the three seasons and included sociodemographic and behavioural questions (number of sexual partners, condom use, STI history and injecting drug use) and also on HIV-testing history (previous testing experience and time since last test). The questions assessing involvement in gay culture, self-identified sexual orientation, last testing location, main reason for testing today, reason for testing in the programme and future testing intentions were only included during certain periods that will be specified as table footnotes. For those with limited proficiency in Spanish, a form was designed to collect basic socio-demographic, behavioural and HIVtesting history data, in English and French.
In season 1, those with a reactive rapid test were referred to a collaborating STI/HIV diagnostic centre or advised to see their general practitioners. They were asked to give a telephone number in order to obtain their confirmation result and to keep in contact for support during linkage to care. Confirmation results and $\mathrm{CD} 4$ count were obtained through direct contact with either the individual or the collaborating diagnostic centre. To shorten the diagnostic process and facilitate linkage to care, from season 2 onwards blood was extracted at the mobile unit and immediately sent to a collaborating STI/HIV diagnostic centre for confirmation. Subjects were then contacted and an appointment set for the result communication and, if positive, the collaborating centres performed a clinical and immunological evaluation for antiretroviral therapy (ART) initiation. We considered as 'linked to care' all the individuals who visited a health centre (mainly the collaborating STI/HIV diagnostic centres) to receive the confirmation result or to ask for a confirmation test. Early diagnosis was defined as having a CD4 count of $\geq 350$ cells $/ \mu \mathrm{L}$. Those who revealed during post-test counselling that they had previously tested positive for HIV were excluded from the analysis.

\section{Data analysis}

A descriptive analysis was carried out by stratifying the sample into three groups: women, men who have sex exclusively with women (MSW), and men who have sex with men (MSM). Men included in the latter group were those who reported ever having had sex with men. Using the same stratification, we analysed testing history and other testing-related variables. In the MSM group, a further stratification by serostatus was conducted. Differences between the three groups were assessed using the chi-squared test.

In the analysis of HIV positive individuals, we considered new diagnoses $(n=133)$, those rapid test results with a positive confirmation $(n=114)$ and those for which the confirmation result remains unknown $(n=19)$ (Figure 1). To evaluate the programme's capacity to detect previously undiagnosed HIV infections, we present the distribution of persons tested and the prevalence of infection with its $95 \%$ confidence interval (CI) by programme location. In each location we performed the same analysis by transmission category and in the MSM by place of birth. Due to limited sample sizes this analysis could not be conducted in heterosexuals or injecting drug users (IDU). We also estimated the prevalence of infection by transmission category (regardless of programme location) and in MSM, by age, country of birth and educational level. Within HIV-positive individuals we estimated the percentage linked to care, and the proportion diagnosed at a late stage of infection, both globally and among MSM.

These outcomes are compared with EPI-VIH-network (EPI-VIH) and the Spanish National HIV Surveillance System (SNHSS). EPI-VIH is a sentinel surveillance system based on $20 \mathrm{STI} / \mathrm{HIV}$ clinics located in 19 medium 


\section{FIGURE 1}

Rapid test and confirmation results, availability of data on linkage to care and CD4 count for people who underwent testing in a street-based HIV rapid-testing programme, Spain, 2008-2011

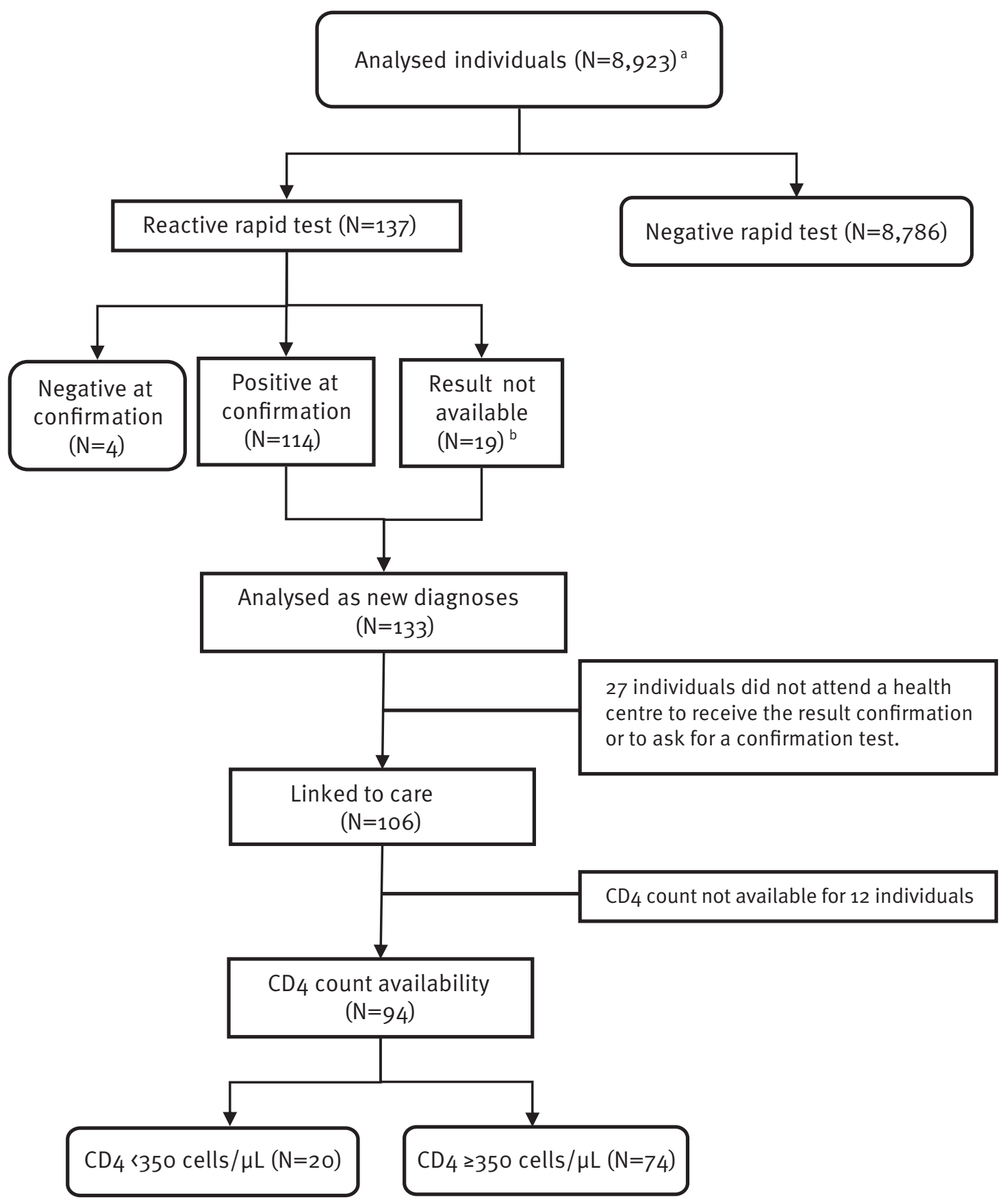

MSM: Men who have sex with men; MSW: Men who have sex with women.

a $n=70$ were not included because they had never had sexual relations or had ever injected drugs ; $=173$ men were excluded because they could not be classified as MSM or MSW.

b Did not attend a collaborating centre and could not be contacted directly to obtain confirmation results, however they were considered new diagnoses in the analysis. 
Number of people tested and prevalence of HIV infection by programme location, transmission group and place of birth, in a street-based HIV rapid-testing programme, Spain, 2008-2011

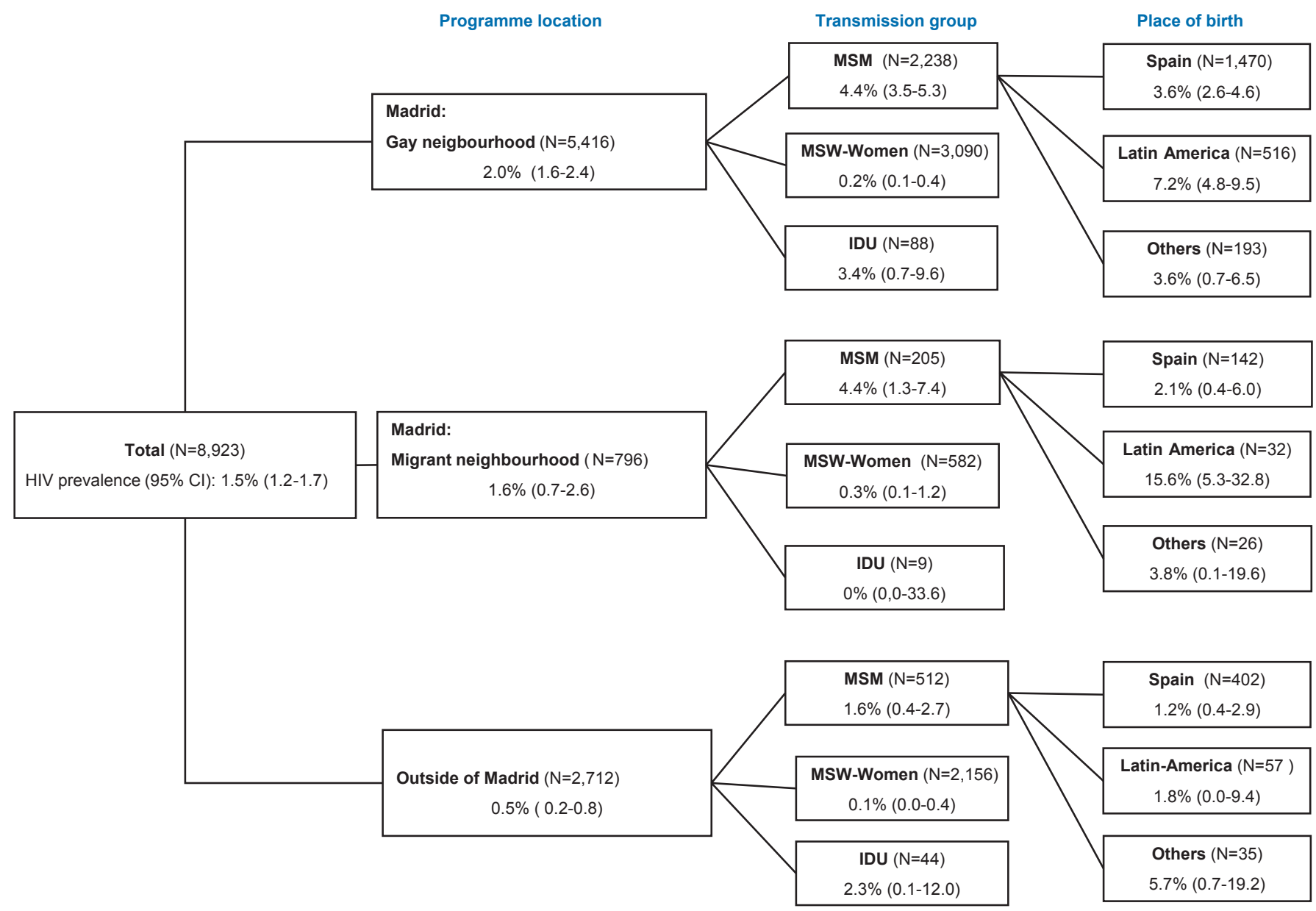

IDU: injecting drug users; MSM: men who have sex with men; MSW: men who have sex exclusively with women.

and large Spanish cities. They offer voluntary, confidential and free-of-charge HIV testing, and some also offer anonymous testing. No legal documents were required during the study period (2008-2011). This system collects some limited information about people tested including the test result [10]. SNHSS collects new HIV diagnoses data reported by 17 of the 19 Spanish autonomous regions ( $71 \%$ of the Spanish population). It is the best approximation of the characteristics of the national epidemic and its evolution [4]. Both EPIVIH and SNHSS information is collected using data collection forms completed by a healthcare professional. When comparing our results with those of both surveillance systems, we took into account available data from the years when the programme was implemented: 2008-2010 in the case of EPI-VIH and 2008-2011 in SNHSS. Given the low number of HIV-positive women and MSW in the programme, the characterisation of HIV-infected individuals was restricted to MSM. The capacity of the programme to reduce periods of undiagnosed infections is gauged by i) analysing whether its good visibility prompted testing in individuals who had not though about it and ii) by analysing testing history and future testing intention of HIV-infected participants. Again, due to sample size limitations these analyses were limited to HIV-positive MSM. The study was approved by the Instituto de Salud Carlos III's institutional review board.

\section{Results}

Sociodemographic, behavioural characteristics and sexual orientation

Of the 9,166 people tested we excluded from the analysis 70 individuals who had never had sexual relations or injected drugs and 173 men who did not answer the question on sexual behaviour and could not be classified in either of the two subgroups (Figure 1). Of the 
TABLE 1

Sociodemographic, sexual identity, gay community involvement and behavioural risk variables of people receiving rapid HIV testing in a street-based programme, Spain, 2008-2011 $(\mathrm{n}=8,923)$

\begin{tabular}{|c|c|c|c|c|c|c|c|c|c|}
\hline & \multicolumn{2}{|c|}{$\begin{array}{c}\text { Women } \\
(\mathrm{n}=3,087)\end{array}$} & \multicolumn{2}{|c|}{$\begin{array}{c}\text { MSW } \\
(n=2,832)\end{array}$} & \multicolumn{2}{|c|}{$\begin{array}{c}\text { MSM } \\
(n=3,004)\end{array}$} & \multicolumn{2}{|c|}{$\begin{array}{c}\text { Total } \\
(\mathrm{n}=8,923)\end{array}$} & \multirow{2}{*}{$\begin{array}{c}p \\
\text { value }^{a}\end{array}$} \\
\hline & $\mathrm{N}$ & $\%$ & $\mathrm{~N}$ & $\%$ & $\mathrm{~N}$ & $\%$ & $\mathrm{~N}$ & $\%$ & \\
\hline \multicolumn{9}{|l|}{ Programme location } & $<0.001$ \\
\hline City of Madrid: gay neighbourhood & 1,708 & 55.3 & 1,429 & 50.5 & 2,277 & 75.8 & 5,414 & 60.7 & n.a \\
\hline City of Madrid: migrant neighbourhood & 288 & 9.3 & 301 & 10.6 & 204 & 6.8 & 793 & 8.9 & n.a \\
\hline Outside of the city of Madrid & 109 & 35.3 & 1,101 & 38.9 & 521 & 17.3 & 2,712 & 30.4 & n.a \\
\hline$<30$ years old & 1,816 & 61.7 & 1,251 & 45.9 & 1,387 & 47.3 & 4,451 & 51.8 & $<0.001$ \\
\hline \multicolumn{9}{|l|}{ Place of birth } & $<0.001$ \\
\hline Spain & 2,042 & 68.2 & 1,793 & 65.1 & 2,037 & 69.7 & 5,872 & 67.7 & n.a \\
\hline Latin America & 664 & 22.2 & 576 & 20.9 & 618 & 21.1 & 1,858 & 21.4 & n.a \\
\hline Others & 287 & 9.6 & 385 & 14.0 & 267 & 9.1 & 939 & 10.8 & n.a \\
\hline Completed a university degree & 1,517 & 49.9 & 1,074 & 38.6 & 1,610 & 54.0 & 4,201 & 47.7 & $<0.001$ \\
\hline \multicolumn{10}{|l|}{ Sexual identity and gay community involvement } \\
\hline \multicolumn{9}{|l|}{ Sexual orientation ${ }^{b}$} & $<0.001$ \\
\hline Homosexual & 84 & 4.6 & 11 & 0.7 & 1,409 & 77.8 & 1,504 & 28.6 & n.a \\
\hline Bisexual & 137 & 7.5 & 15 & 0.9 & 214 & 11.8 & 366 & 6.9 & n.a \\
\hline Heterosexual & 1,599 & 87.9 & 1,610 & 98.4 & 188 & 10.4 & 3,397 & 64.5 & n.a \\
\hline \multicolumn{10}{|l|}{ Relationship with gay culture ${ }^{c}$} \\
\hline Frequenter of gay scene but not a member of a gay CBO & n.a & n.a & n.a & n.a & 1,219 & 63.0 & n.a & n.a & n.a \\
\hline Not related to gay scene & n.a & n.a & n.a & n.a & 499 & 25.8 & n.a & n.a & n.a \\
\hline Member of a gay CBO & n.a & n.a & n.a & n.a & 216 & 11.2 & n.a & n.a & n.a \\
\hline \multicolumn{10}{|l|}{ Behavioural characteristics } \\
\hline Ever injected drugs & 61 & 2.1 & 115 & 4.4 & 76.0 & 2.7 & 252 & 3.0 & $<0.001$ \\
\hline Diagnosed with an STI (last 12 months) & 167 & 9.5 & 71 & 4.9 & 242 & 13.5 & 480 & 9.6 & $<0.001$ \\
\hline \multicolumn{9}{|l|}{ Number of heterosexual partners (last 12 months) } & $<0.001$ \\
\hline $0-1$ & 1,135 & 39.8 & 675 & 27.5 & 2,361 & 87.7 & 4,171 & 52.2 & n.a \\
\hline 2 & 594 & 20.8 & 514 & 21.0 & 100 & 3.7 & 1,208 & 15.1 & n.a \\
\hline $3-4$ & 648 & 22.7 & 626 & 25.6 & 103 & 3.8 & 1,377 & 17.2 & n.a \\
\hline$\geq 5$ & 473 & 16.6 & 635 & 25.9 & 130 & 4.8 & 1,238 & 15.5 & n.a \\
\hline Unprotected sex with heterosexual occasional partners (last 12 months) & 1,435 & 50.6 & 1,230 & 51.0 & 212 & 7.9 & 2,877 & 36.3 & $<0.001$ \\
\hline \multicolumn{10}{|l|}{ Number of homosexual partners (last 12 months) } \\
\hline $0-1$ & n.a & n.a & n.a & n.a & 570 & 20.3 & n.a & n.a & n.a \\
\hline $2-4$ & n.a & n.a & n.a & n.a & 809 & 28.8 & n.a & n.a & n.a \\
\hline $5-9$ & n.a & n.a & n.a & n.a & 538 & 19.2 & n.a & n.a & n.a \\
\hline $10-19$ & n.a & n.a & n.a & n.a & 442 & 15.8 & n.a & n.a & n.a \\
\hline$\geq 20$ & n.a & n.a & n.a & n.a & 447 & 15.9 & n.a & n.a & n.a \\
\hline Unprotected sex with homosexual occasional partners (last 12 months) & n.a & n.a & n.a & n.a & 991 & 36.5 & n.a & n.a & n.a \\
\hline
\end{tabular}

CBO: community-based organisation; MSM: men who have sex with men; MSW: men who have sex exclusively with women; n.a.; not applicable; STI: sexually transmitted infection.

The programme was conducted during three periods: May 2008-December 2008 (season 1, 62 days in total), July $2009-J u l y ~ 2010$ (season 2, 65 days) and November 2010-December 2011 (season 3, 35 days).

a $\mathrm{p}$ value refers to chi-squared test between MSM, Women, MSW.

b Included in season 2 onwards.

Included in the first season, but starting October 2008 . 
8,923 analysed (Table 1), 34.6\% were women, $31.7 \%$ MSW and $33.7 \%$ MSM. Some $60.7 \%$ were tested in Madrid's gay neighbourhood, $8.9 \%$ in Madrid's migrant neighbourhood and $30.4 \%$ outside of Madrid (Table 1 ). The proportion of MSM was notably higher in the gay neighbourhood than in the other two areas (Figure 2). Fifty two percent were under 30 years of age, $21.4 \%$ were born in Latin America (defined as people born in countries of the American continent where Spanish or Portuguese is the main national language), $10.8 \%$ in other countries and $47.7 \%$ had a college degree. During the previous 12 months, $50.6 \%$ of the women and $51 \%$ of the MSW had had unprotected sex with heterosexual occasional partners. Unprotected sex with homosexual occasional partners was reported by $36.5 \%$ of the MSM. Three per cent reported having ever injected drugs (Table 1).

\section{Testing related information}

Twenty six per cent of the MSM had never been tested before (18.4\% among new diagnoses); this percentage was higher in women (63.8\%) and MSW (61.5\%). MSM had the shortest time between previous and current testing: $40.2 \%$ of MSM had tested in the previous 12 months (although $26.3 \%$ of HIV-positive MSM had last been tested two or more years previously). The most common location for most recent test was primary care $(26.8 \%)$ and having had unprotected sex with occasional partners (34.1\%) was the most common reason for testing that day. Testing as a part of a periodical routine was the second most cited reason (12.8\%), mainly because $24 \%$ of the MSM reported it. This percentage was 4 times lower in the HIV-positive MSM (6.3\%) (Table 2). Some $57.5 \%$ of all attendees got tested in the programme because they passed by, saw it and decided to take it. Regarding testing intentions, $\mathbf{2 2 . 2} \%$ said they probably or certainly would not have been tested in the next 12 months if they had not done so that day. This percentage was lower in MSM (10.4\%), and even lower in MSM diagnosed with HIV (3.1\%) (Table 2).

Analysis of newly diagnosed individuals: comparison with EPI-VIH and SNHSS

The overall HIV prevalence was $1.5 \%$, ranging from $0.5 \%$ outside the city of Madrid to $2.0 \%$ in Madrid's gay neighbourhood. Prevalence by transmission category was highest in the MSM group (4.4\% in Madrid locations) and within the MSM group, in MSMs born in Latin America (prevalence reaching $15.6 \%$ in the migrant neighbourhood) (Figure 2).

Positivity rates both overall (1.5\%) and in MSM (3.9\%) were lower than in EPI-VIH (2.7\% and $8 \%$ respectively). Regarding the characteristics of the 133 new diagnoses, $89.2 \%$ were in MSM compared to $78.0 \%$ in EPI-VIH and $56.0 \%$ in SNHSS. Our programme showed a greater percentage of new diagnoses in MSM under 30 years of age $(49.6 \%)$ than EPI-VIH (43.2\%) and SNHSS (34.2\%). The programme also presented a higher percentage of new HIV diagnoses in Latin Americans (37.7\%) than
EPI-VIH (21.8\%) and SNHSS (27.1\%), and a higher educational level (Table 3).

Overall, $79.7 \%$ of individuals newly diagnosed with HIV in this programme were linked to care $(83.6 \%$ in MSM) and CD4 count was known for $70.7 \%$ of the newly diagnosed cases (74.1\% in the MSM group) (Figure 1 ). Of those with $\mathrm{CD}_{4}$ count available, $21.3 \%$ had $<350 \mathrm{CD}_{4}$ cells/ $\mu \mathrm{L}$ (Figure 3), which is $17.8 \%$ lower than in EPIVIH (25.9\%), and 61.1\% lower than in SNHSS (54.8\%). In MSM, delayed diagnosis (20.9\%) was $10.4 \%$ lower than in EPI-VIH (23.3\%), and $46 \%$ lower than in SNHSS (38.6\%) (Figure 3).

\section{Discussion}

The programme described in this paper reached a diverse and under-tested population. However, it diagnosed MSM almost exclusively and presented very low positivity rates when conducted outside of Madrid. We found that the prevalence of infection was half than that of EPI-VIH and that HIV-positive MSM were younger, more frequently from Latin America and had a higher level of education than in EPI-VIH. Compared with SNHSS, MSM diagnosed in the programme were also younger and more frequently from Latin America. The good visibility of the mobile unit led to reduced periods of undiagnosed infection in six out of ten MSM who happened to see it and decided to get tested. The programme was able to reach and diagnose a group of MSM who did not test for HIV with the recommended frequency. Eight out of ten were linked to care and the percentage of late diagnoses was similar to EPI-VIH but half of what was reported in SNHSS.

This study contributes substantially to the scarce body of European literature that analyses community-based testing. It evaluates a programme that is different in terms of its setting and the population it served. Comparing the programme with other healthcare settings puts the results into perspective, which has rarely been done before. Finally, we evaluate how this programme's good visibility could contribute to the control of the epidemic.

Most of the European-based published studies have evaluated programmes where MSM are the target population [11-15]. This is one of the few not specifically focused on them. The good visibility of the programme, and its deployment in settings not related to the gay community may have prompted testing in lower-risk individuals who otherwise would not have thought of it. In fact, two thirds of those who took the test in the mobile unit were either MSW or women, and within these two groups, around six out of 10 had never tested for HIV before. This capacity of the programme to promote HIV testing in populations with no previous testing history has been described elsewhere [16].

The overall prevalence is similar to that found by the handful of studies that evaluate programmes outside clinical settings which do not target vulnerable 
TABLE 2

Testing history, reasons for testing and future testing intentions of people who underwent testing in a street-based HIV rapid-testing programme, Spain, 2008-2011 $(n=8,923)$

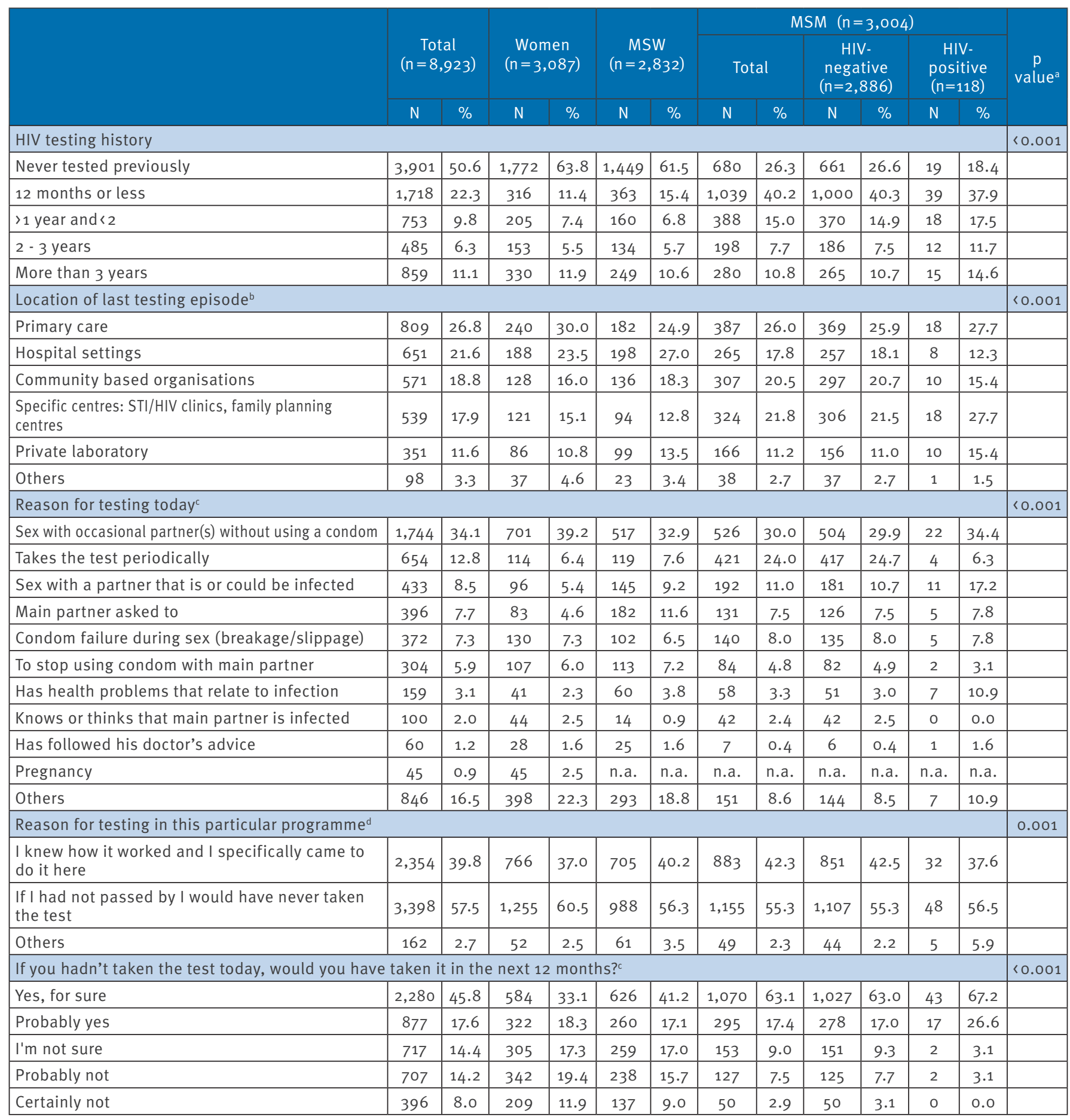

MSW: men who have sex exclusively with women; MSM: men who have sex with men; n.a.: not applicable.

The programme was conducted during three periods: May 2008-December 2008 (season 1, 62 days in total), July 2009-July 2010 (season 2, 65 days) and November 2010-December 2011 (season 3, 35 days).

a $\mathrm{p}$ value referred to chi-squared test between MSM, women, MSW.

b Variable not included in season 3.

Included in season 2 onward.

d Included in season 1 and 2. In season 3 it was included starting from June 2011. 
Comparison of people newly diagnosed with HIV by a street-based HIV rapid-testing programme, Spain, 2008-2011, with those from EPI-VIH (2008-2010) and the Spanish National HIV Surveillance System (2008-2011) (SNHSS)

\begin{tabular}{|c|c|c|c|c|c|c|c|c|c|c|}
\hline \multirow{3}{*}{ All } & \multicolumn{4}{|c|}{ Street-based programme } & \multicolumn{4}{|c|}{ EPI-VIH network } & \multicolumn{2}{|l|}{ SNHSS } \\
\hline & \multirow{2}{*}{$\begin{array}{c}N \\
133 \\
\end{array}$} & \multirow{2}{*}{$\begin{array}{c}\% \\
100.0\end{array}$} & \multicolumn{2}{|c|}{$\begin{array}{l}\text { HIV + prevalence } \\
(95 \% \mathrm{CI})\end{array}$} & \multirow{2}{*}{$\begin{array}{c}N \\
2014\end{array}$} & \multirow{2}{*}{$\begin{array}{c}\% \\
100.0\end{array}$} & \multicolumn{2}{|c|}{$\begin{array}{l}\text { HIV + prevalence } \\
\quad(95 \% \mathrm{CI})\end{array}$} & \multirow{2}{*}{$\frac{N}{10517}$} & \multirow{2}{*}{$\begin{array}{c}\% \\
100.0\end{array}$} \\
\hline & & & 1.5 & $(1.2-1.7)$ & & & 2.7 & $(2.6-2.8)$ & & \\
\hline Injecting drug users & 4 & 3.1 & 2.8 & $(0.8-7.0)$ & 104 & $5 \cdot 3$ & 10.7 & $(8.7-12.7)$ & 734 & 7.7 \\
\hline Heterosexual contact & 10 & 7.7 & 0.2 & $(0.1-0.3)$ & 329 & 16.7 & 0.6 & $(0.5-0.7)$ & 3,453 & 36.3 \\
\hline Heterosexual women & 4 & 3.1 & 0.1 & $(0.0-0.3)$ & 154 & 7.8 & 0.5 & $(0.4-0.6)$ & 1,620 & 17.0 \\
\hline Heterosexual men & 6 & 4.6 & 0.2 & $(0.0-0.4)$ & 175 & 8.9 & 0.7 & $(0.6-0.9)$ & 1,833 & 19.3 \\
\hline Men who have sex with men & 116 & 89.2 & 3.9 & $(3.2-4.6)$ & 1,531 & 78.0 & 8.0 & $(7.6-8.4)$ & 5,327 & 56.0 \\
\hline \multicolumn{11}{|c|}{ Men who have sex with men: characterisation } \\
\hline \multicolumn{11}{|l|}{ Age in years } \\
\hline$<25$ & 31 & 27.0 & 4.5 & $(2.9-6.2)$ & 289 & 18.2 & 8.2 & $(7.2-9.3)$ & 740 & 13.9 \\
\hline $25-29$ & 26 & 22.6 & 3.9 & $(2.3-5.4)$ & 396 & 25.0 & 12.3 & $(10.9-13.7)$ & 1,079 & 20.3 \\
\hline $30-39$ & 43 & 37.4 & 4.3 & $(3.0-5.7)$ & 608 & 38.3 & 12.8 & $(11.6-14.0)$ & 2,045 & 38.3 \\
\hline$\geq 40$ & 15 & 13.1 & 2.8 & $(1.3-4.2)$ & 291 & 18.4 & 12.0 & $(10.4-13.8)$ & 1,463 & 27.5 \\
\hline \multicolumn{11}{|l|}{ Country of birth } \\
\hline Spain & 61 & 53.5 & 3.0 & $(2.3-3.8)$ & 1,072 & 67.6 & 9.2 & $(8.6-9.9)$ & 3,408 & 64.0 \\
\hline Latin-America & 43 & 37.7 & 7.1 & $(5.0-9.2)$ & 424 & 26.7 & 21.8 & $(19.7-24.0)$ & 1,444 & 27.1 \\
\hline Others & 10 & 8.8 & 3.9 & $(1.3-6.5)$ & 90 & 5.7 & 9.7 & $(7.5-12.3)$ & 475 & 8.9 \\
\hline \multicolumn{11}{|l|}{ Educational level } \\
\hline Primary/None & 6 & 5.3 & 8.2 & $(2.3-4.1)$ & 266 & 18.3 & n.av. & n.av. & n.av. & n.av. \\
\hline Secondary & 57 & 50.0 & 4.5 & $(3.3-5.7)$ & 629 & 43.3 & n.av. & n.av. & n.av. & n.av. \\
\hline University & 51 & 44.7 & 3.2 & $(1.2-15.2)$ & 556 & 38.3 & n.av. & n.av. & n.av. & n.av. \\
\hline
\end{tabular}

$\mathrm{Cl}$ : confidence interval; EPI-VIH: network of 20 Spanish STI/HIV diagnostic clinics; n.av.: data not available; SNHSS: Spanish National HIV Surveillance System.

populations [17-20]. It varied by location and was higher in the city of Madrid. The capacity of the programme to reach undiagnosed individuals was substantially lower than in EPI-VIH, which is consistent with the only study comparing a CBO with diagnostic clinics in the past [11]. Almost all of the new diagnoses were in the MSM group which is unsurprising in a country where they are the most vulnerable population for HIV infection. However, their weight among the new diagnoses is much higher than in the national figures represented by SNHSS, and also higher than in EPI-VIH.

Prevalence in heterosexuals was three times lower than in EPI-VIH and very similar to the prevalence found by another study conducted in primary care in Madrid [21]. This raises the question: is it appropriate to carry out programmes of this nature in locations frequented by lower risk groups? The question is even more pertinent if we consider that, while cost per diagnosis was not assessed, the only example we found concluded that it was considerably higher in outreach settings than in STI/HIV clinics [22].

To evaluate the programme's potential to prevent onward transmission, we must consider factors other than prevalence of infection. Reducing the time an infection remains undiagnosed as a result of the implementation of the programme is a key factor: the sooner an infection is detected, the sooner the community will benefit from viral load reductions and behavioural change. In this sense, good visibility translated into an earlier diagnosis in more than half of the HIVpositive MSM who were not actively seeking to be tested that day: they happened to see the mobile unit and decided to test. According to testing intentions, the time of undiagnosed infection would be reduced by up to one year: almost all of the HIV-infected individuals reported that they would have sought testing in the next 12 months. According to their testing history, however, the gain would be higher: two out of 10 had never tested before and an additional $25 \%$ had tested more than two years ago, which is much longer than recommended for this group [8]. It is noteworthy that very few of the HIV-positive MSM reported having tested as a part of a routine check-up. Reaching out to high-risk populations who have not internalised testing as a part of a routine could shorten the time from diagnosis to infection and therefore reduce onward transmission.

The programme also showed a capacity to promote early diagnosis in MSM: only two of 10 hadCD4 1350 cells $/ \mu \mathrm{L}$, which represents a remarkable improvement when compared with SNHSS. Likewise, programme attendees were also diagnosed earlier than EPI-VIH 


\section{FIGURE 3}

Percentage of newly diagnosed HIV infections with CD4 count $<350$ cells/ $\mu \mathrm{L}$ in a street-based HIV rapid-testing programme, Spain (2008-2011) compared with EPI-VIH (2008-2010) and the Spanish National HIV Surveillance System (2008-2011)

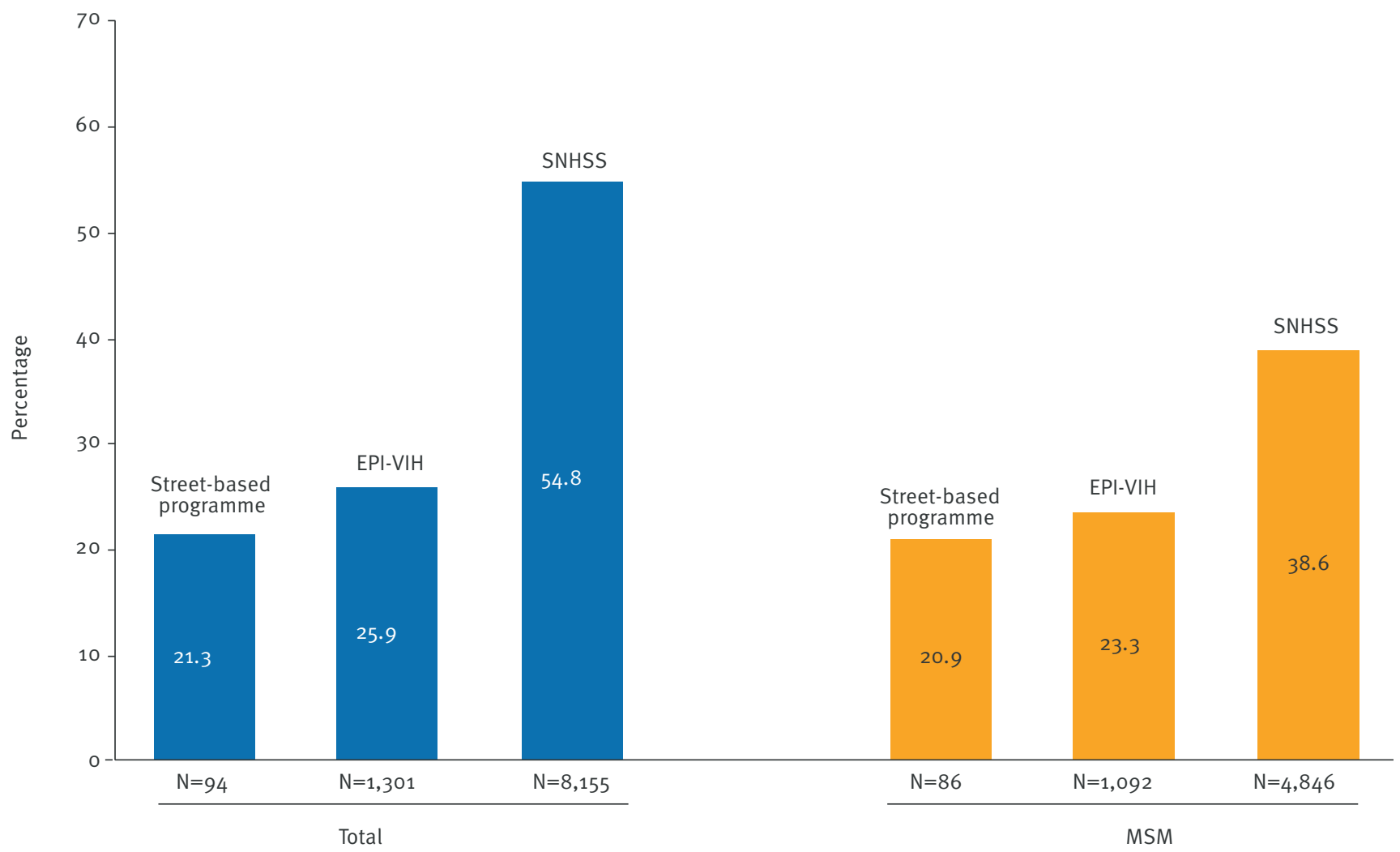

EPI-VIH: network of 20 Spanish HIV/STI diagnostic clinics; MSM: Men who have sex with men; SNHSS: Spanish National HIV Surveillance System.

Percentages calculated on those with data available on $\mathrm{CD}_{4}$ count

patients but differences were much smaller. Evidently, as the percentage of delayed diagnosis drops there is less room for improvement. It is also true that HIVpositive MSM were younger and had a higher level of education than in EPI-VIH and SNHSS. The association of delayed diagnosis with increasing age and, in men, with low educational level has been described previously $[23-25,26]$, which means that the programme is reaching subpopulations that are a priori at lower risk of being diagnosed late. On the other hand, in comparison with EPI-VIH and SNHSS, the programme was good at reaching Latin Americans. In Spain, unlike other European countries, they are the largest migrant group, but it is also true that delayed diagnosis in this group is similar to that of the Spanish-born population [4].

Obviously, diagnosis is useless if it is not followed by linkage to the health system for ART eligibility. The linked-to-care percentage was similar to that of the few European studies reporting this outcome $[11,12,15]$ but the definitions used in those studies are not clearly stated and precautions should be taken when comparing results.

The present study has several limitations. First, there is the possibility that some of those with unavailable data on confirmation result did not attend a health centre for this purpose. However, given that access to testing in Spain was universal and performed confidentially in a wide range of settings, we believe that this possibility is minimal. Second, metrics used in 'linkage to care' definitions are heterogeneous. Some are based on clinic visits (as for this study) and some on laboratory monitoring tests. Nevertheless, they always include a time period since diagnosis to either first clinic visit or first laboratory monitoring test [27]. Unfortunately, this parameter was not assessed in the present study and, if included, our 'linkage to care' percentage would probably be lower. Third, when interpreting late diagnosis figures, we should keep in mind that they are calculated by factoring in only those individuals for whom we have a $\mathrm{CD}_{4}$ count. It is not known whether those with no data available are more affected 
by late diagnosis. However, the effect of this limitation in the comparison with EPI-VIH is limited, as the proportion of individuals with an unknown $\mathrm{CD}_{4}$ count (33.4\%) is similar. Conversely, it might have a greater influence when comparing our study with SNHSS, since the percentage is notably lower (13\%). Finally, our data is based on self-reports and could be affected by social desirability bias. However, the use of an anonymous and self-administered questionnaire may have helped to obtain franker answers in the sensitive aspects of the survey.

By giving individuals the chance to rapidly check their serological status, this highly visible programme helped to diagnose a high proportion of individuals who were not actively seeking to get tested. Thus, it diminished the period during which the infection remains undiagnosed and therefore has the potential to reduce onward transmission in a population with high levels of sexual risk behaviours who are not testing with the recommended frequency. All this translated into a substantial contribution to early diagnosis in the MSM group in which late presentation at the population level - despite being lower than in other groups is still too high. However, the HIV prevalence is notably lower if we compare it with a clinical setting serving atrisk populations. In order to improve its performance from a cost perspective, this programme should concentrate in locations highly transited by MSM.

\section{The Madrid HIV rapid testing group}

Jesús Oliva, Mónica Ruiz, María Elena Rosales-Statkus, Jorge Gutiérrez, Rebeca Sánchez and Jorge Álvarez.

\section{Acknowledgements}

This study was funded by Fundación para la investigación y la prevención del SIDA en España (FIPSE-240961/10) and by the Fondo de Investigación Sanitaria (FIS-Plog/1706)

\section{Conflicts of interest}

None declared

Authors' contributions

MJ Belza and LF designed the study and took overall responsibility of the project, JH, MJ Belza wrote the manuscript, JH, SFB, AD, did the analysis and interpretation of data, AD, MJ Bravo, LF critically revised the manuscript and contributed important intellectual content,

Madrid Rapid HIV testing Group made contributions to the study design, and participated in the acquisition of data.

\section{References}

1. Supervie V, Ndawinz JD, Lodi S, Costagliola D. The undiagnosed HIV epidemic in France and its implications for HIV screening strategies. AIDS. 2014;28(12):1797-804. http:// dx.doi.org/10.1097/QAD.0000000000000270 PMID:24681416

2. Aghaizu A, Brown AE, Nardone A, Gill ON, Delpech VC. contributors. HIV in the United Kingdom 2013 Report: data to end 2012. November 2013. London: Public Health England; 2014 .

3. Hamers FF, Phillips AN. Diagnosed and undiagnosed HIVinfected populations in Europe. HIV Med. 2008;9(s2) Suppl 2;6-12. http://dx.doi.org/10.1111/j.1468-1293.2008.00584.x PMID:18557863

4. Área de vigilancia de VIH y conductas de riesgo. Vigilancia Epidemiológica del VIH/sida en España: Sistema de Información sobre Nuevos Diagnósticos de VIH y Registro Nacional de Casos de Sida, 2007-2011 [Internet]. Madrid: Secretaría del Plan Nacional sobre el Sida/Centro Nacional de Epidemiología; 2012. [Accessed March 2013]. Available from: http://www.isciii.es/ISCIII/es/contenidos/fd-servicioscientifico-tecnicos/fd-vigilancias-alertas/fd-enfermedades/ fd-sida/Informe-VIH-sida-Junio-2012.pdf

5. Kitahata MM, Gange SJ, Abraham AG, Merriman B, Saag MS, Justice AC, et al.; NA-ACCORD Investigators. Effect of early versus deferred antiretroviral therapy for HIV on survival. $\mathrm{N}$ Engl J Med. 2009;360(18):1815-26. http://dx.doi.org/10.1056/ NEJMoao807252 PMID:19339714

6. Rodger AJ, Lodwick R, Schechter M, Deeks S, Amin J, Gilson R, et al.; INSIGHT SMART, ESPRIT Study Groups. Mortality in well controlled HIV in the continuous antiretroviral therapy arms of the SMART and ESPRIT trials compared with the general population. AIDS. 2013;27(6):973-9. http://dx.doi.org/10.1097/ QAD.obo13e32835cae9c PMID:23698063

7. Marks G, Crepaz N, Janssen RS. Estimating sexual transmission of HIV from persons aware and unaware that they are infected with the virus in the USA. AIDS. 2006;20(10):144750. http://dx.doi.org/10.1097/01.aids.0000233579.79714.8d PMID:16791020

8. European Centre for Disease Prevention and Control (ECDC). HIV testing: increasing uptake and effectiveness in the European Union [Internet]. Stockholm: ECDC; 2010. [Accessed March 2013]. Available from: http://ecdc.europa.eu/en/ publications/Publications/101129_TER_HIV_testing_evidence. pdf

9. Real Decreto-ley $16 / 2012$, de 20 de Abril, de medidas urgentes para garantizar la sostenibilidad del Sistema Nacional de Salud y mejorar la calidad y seguridad de sus prestaciones [Royal Decree-Law 16/2012, 20 th April Urgent measures to ensure the sustainability of the national health system and Improve the quality and safety of its services]. Num. 98 Martes 24 de Abril de 2012. Boletín Oficial del Estado, 2012. Spanish.

10. Grupo EPI-VIH. Estudio prospectivo de prevalencia de VIH en pacientes de una red de centros de diagnóstico de $\mathrm{VIH}$, 2000-2010. [Prospective study of HIV prevalence in patients in a network of HIV diagnostic centres, 2000-2010]. Madrid: Centro Nacional de Epidemiología; 2012. Spanish. [Accessed March 2013]. Available from: http://www.isciii.es/ISCIII/es/ contenidos/fd-servicios-cientifico-tecnicos/fd-vigilanciasalertas/fd-enfermedades/fd-sida/Informe-EPI-VIH-2000-2010. pdf

11. Bailey AC, Roberts J, Weatherburn P, Hickson FC, Reid DS Fisher M, et al. Community HIV testing for men who have sex with men: results of a pilot project and comparison of service users with those testing in genitourinary medicine clinics. Sex Transm Infect. 2009;85(2):145-7. http://dx.doi.org/10.1136/ sti.2008.032359 PMID:19060035

12. Champenois K, Le Gall JM, Jacquemin C, Jean S, Martin C, Rios L, et al. ANRS-COM'TEST: description of a community-based HIV testing intervention in non-medical settings for men who have sex with men. BMJ Open. 2012;2(2):eo00693. http:// dx.doi.org/10.1136/bmjopen-2011-000693 PMID:22466158

13. Gumy C, Jeannin A, Balthasar H, Huissoud T, Jobin V, Häusermann $M$, et al. Five-year monitoring of a gay-friendly voluntary counselling and testing facility in Switzerland: who got tested and why? BMC Public Health. 2012;12(1):422. http:// dx.doi.org/10.1186/1471-2458-12-422 PMID:22682345

14. Hurtado I, Alastrue I, García de Olalla P, Albiach D, Martín $M$, Pérez-Hoyos S. Intervención preventiva en lugares de interacción social de hombres que mantienen relaciones sexuales con otros hombres. [Preventive intervention in venues for interaction used by men who have sex with men] Gac Sanit. 2010;24(1):78-80. Spanish. http://dx.doi.org/10.1016/j. gaceta.2009.05.014

15. Meulbroek M, Ditzel E, Saz J, Taboada H, Pérez F, Pérez A, et al. BCN Checkpoint, a community-based centre for men who have sex with men in Barcelona, Catalonia, Spain, shows high efficiency in HIV detection and linkage to care. HIV Med. 2013;14(Suppl 3):25-8. http://dx.doi.org/10.1111/hiv.12054 PMID:24033899

16. Fernández-Balbuena S, de la Fuente L, Hoyos J, RosalesStatkus ME, Barrio G, Belza MJ, et al.; Madrid Rapid HIV testing Group. Highly visible street-based HIV rapid testing: is it an attractive option for a previously untested population? 
A cross-sectional study. Sex Transm Infect. 2014;90(2):1128. http://dx.doi.org/10.1136/sextrans-2013-051234 PMID:24234073

17. de la Fuente L, Delgado J, Hoyos J, Belza MJ, Alvarez J, Gutiérrez J, et al.; Madrid Rapid HIV Testing Group. Increasing early diagnosis of HIV through rapid testing in a street outreach program in Spain. AIDS Patient Care STDS. 2009;23(8):625-9. http://dx.doi.org/10.1089/apc.2009.0019 PMID:19591605

18. Darling KE, Diserens EA, N'garambe C, Ansermet-Pagot A, Masserey $E$, Cavassini $M$, et al. A cross-sectional survey of attitudes to HIV risk and rapid HIV testing among clients of sex workers in Switzerland. Sex Transm Infect. 2012;88(6):4624. http://dx.doi.org/10.1136/sextrans-2012-050489 PMID:22628660

19. Fernàndez-Lopez L, Rifà B, Pujol F, Becerra J, Pérez M, Meroño $M$, et al. Impact of the introduction of rapid HIV testing in the Voluntary Counselling and Testing sites network of Catalonia, Spain. Int J STD AIDS. 2010;21(6):388-91. http://dx.doi. org/10.1258/ijsa.2008.008459 PMID:20606218

20. Gorostiza I, Elizondo López de Landache I, Braceras Izagirre L. Programa de cribado de VIH/sida en las oficinas de farmacia en la Comunidad Autónoma del País Vasco [HIV/AIDS screening program in community pharmacies in the Basque Country (Spain)]. Gac Sanit. 2013;27(2):164-6. Spanish. http://dx.doi. org/10.1016/j.gaceta.2012.02.010 PMID:22554455

21. Moreno S, Ordobas M, Sanz JC, Ramos B, Astray J, Ortiz M, et al. Prevalence of undiagnosed HIV infection in the general population having blood tests within primary care in Madrid, Spain. Sex Transm Infect. 2012 Nov;88(7):522-4. http://dx.doi. org/10.1136/sextrans-2012-050481 PMID:22651927

22. Shrestha RK, Clark HA, Sansom SL, Song B, Buckendahl H, Calhoun CB, et al. Cost-effectiveness of finding new HIV diagnoses using rapid HIV testing in community-based organizations. Public Health Rep. 2008;123(Suppl 3):94-100. PMID:19166093

23. Girardi E, Sabin CA, Monforte AD. Late diagnosis of HIV infection: epidemiological features, consequences and strategies to encourage earlier testing. J Acquir Immune Defic Syndr. 2007;46(Suppl 1):S3-8. http://dx.doi.org/10.1097/01. qai.0000286597.57066.2b PMID:17713423

24. Oliva J, Galindo S, Vives N, Arrillaga A, Izquierdo A, Nicolau $A$, et al. Retraso diagnóstico de la infección por el virus de la inmunodeficiencia humana en España. [Delayed diagnosis of HIV infection in Spain]. Enferm Infecc Microbiol Clin. 2010;28(9):583-9. Spanish. http://dx.doi.org/10.1016/j. eimc.2010.02.013 PMID:20541845

25. Smit C, Hallett TB, Lange J, Garnett G, de Wolf F. Late entry to HIV care limits the impact of anti-retroviral therapy in The Netherlands. PLoS One. 2008;3(4):e1949.

26. Sobrino-Vegas $P$, Rodríguez-Urrego J, Berenguer J, Caro-Murillo AM, Blanco JR, Viciana P, et al.; CoRIS. Educational gradient in HIV diagnosis delay, mortality, antiretroviral treatment initiation and response in a country with universal health care. Antivir Ther. 2012;17(1):1-8. http://dx.doi.org/10.3851/IMP1939 PMID:22267463

27. Keller SC, Yehia BR, Eberhart MG, Brady KA. Accuracy of definitions for linkage to care in persons living with HIV. J Acquir Immune Defic Syndr. 2013;63(5):622-30. http://dx.doi. org/10.1097/QAl.ob013e3182968e87 PMID:PMC3796149 